\title{
MANAGEMENT OF ENDOCRINE DISEASE Quality of life tools for the management of pituitary disease
}

\section{Susan M Webb, Iris Crespo, Alicia Santos, Eugenia Resmini, Anna Aulinas and Elena Valassi}

Hospital Sant Pau, IIB-Sant Pau, Research Center for Pituitary Diseases, Centro de Investigación Biomédica en Red de Enfermedades Raras (CIBERER, Unidad 747), ISCIII, and Universitat Autònoma de Barcelona (UAB), Barcelona, Spain
Correspondence should be addreesed to S M Webb

Email

swebb@santpau.cat

\begin{abstract}
Background: In the last few years, quality of life (QoL) has become an outcome measure in patients with pituitary diseases.

Objective: To describe the available data on QoL impairment evaluated with questionnaires in patients with pituitary diseases.

Design: Critical review of the pertinent literature and pragmatic discussion of available information.

Methods: Selection of relevant literature from PubMed and WOK, especially from the last 5 years and comprehensive analysis.

Results: QoL is impaired in all pituitary diseases, mostly in acromegaly and Cushing's disease (similar to other causes of Cushing's syndrome), but also in non-functioning pituitary adenomas and prolactinomas, especially in the active phase of the disease. Nevertheless, even after endocrine 'cure', scores tend to be below normative values, indicative of residual morbidity after hormonal control. The presence of hypopituitarism worsens subjective QoL perception, which can improve after optimal substitution therapy, including recombinant human growth hormone, when indicated. Conclusions: To improve the long-term outcome of pituitary patients, helping them to attain the best possible health, it appears desirable to include subjective aspects captured when evaluating QoL, so that the affected dimensions are identified and if relevant treated. Additionally, being aware that treatment outcome may not always mean complete normalisation of physical and mental issues related to QoL can be a first step to adaptation and conforming to this new status.
\end{abstract}

\section{Invited Author's profile}

Susan M Webb is Senior Consultant Endocrinologist in the Hospital Sant Pau, and Professor of Medicine at the Universitat Autonoma de Barcelona, Spain. She runs the Neuroendocrine Clinic and the Pituitary Disease network of excellence research group (CIBERER unit 747), and is interested in the long-term consequences of pituitary diseases and evaluation of health-related quality of life. She coordinates the European Registry on Cushing's Syndrome (ERCUSYN) initially funded by the EU. She has been a member of the European Union Committee of Experts on Rare Diseases (EUCERD), and is currently the Scientific Assistant Director of CIBERER and President of the Rare Disease Advisory Committee of the Catalan health system CatSalut.

() 2017 European Society of Endocrinology Printed in Great Britain
Published by Bioscientifica Ltd. 


\section{Introduction}

As therapeutic options improve for pituitary adenomas, most can be treated to control hyperfunction, mass effects and pituitary insufficiency. Thus, one tends to think we are capable of 'curing' patients with these diseases. However persistent complaints are often encountered, despite control or cure of hormonal excess, relief of mass effects on surrounding tissues and adequate substitution therapy of hypopituitarism, so they often cannot be considered 'completely healthy' $(1,2)$. Multisystem morbidity, especially in treated acromegaly or Cushing's syndrome related to irreversible effects of prior exposure to GH/IGF-1 excess or hypercortisolism, as well as increased mortality may still be present, all of which negatively affect health-related quality of life (QoL). Awareness of these impairments has only really come to light in the last decade, but it is the first step to consider therapeutic intervention, which should lead in the future to improve long-term prognosis and QoL.

\section{What is QoL?}

There is no clear and short definition for all the concepts included in 'health-related quality of life (QoL)'. It refers to individual well-being and how patients perceive their physical, emotional and social health. Subjects will value their QoL taking into account their expectations, standards and goals, as well as emotional, physical and social aspects of their lives that might be affected if a disease is present. Thus, measurements of QoL lead to the evaluation of a particular person's well-being, including individual feelings, concerns, responses and functioning in daily life (3).

\begin{abstract}
Acromegaly
Diagnostic delay, longer disease duration, persistent comorbidities, sexual dysfunction, symptomatic osteoarthritis and/or joint complaints, musculoskeletal pain, restless legs syndrome, poorer physical ability, clumsy and/or numb hands, appearance, hypertension, rural healthcare environment (worse than in urban areas), emergence of growth hormone deficiency, current medical therapy - especially chronic injections - (as opposed to surgical cure), psychopathology (mainly anxiety-related traits, reduced novelty-seeking behaviour and impulsivity; more harm-avoidance and neuroticism, with high social conformity)
\end{abstract}

\section{Cushing's Sd}

Adrenal insufficiency, current medical treatment, frequent check-ups, fatigue/weakness, physical appearance, emotional lability, cognitive problems, sleeping difficulties, anxiety, shorter duration of remission, age at diagnosis, adrenalectomy

\section{Common to all PA}

Older age, female gender, depressive symptoms, hypopituitarism including GH deficiency, active disease (i.e., hormone hypersecretion), negative illness perceptions, radiotherapy, tumour recurrence, frequent check-ups hyperprolactinemia,

hypogonadism, reproductive

i m pa irment, sexual dysfunction, decreased libido, social isolation, emotional disturbances, low vitality, more shyness and neuroticism, less novelty-seeking and extraversion
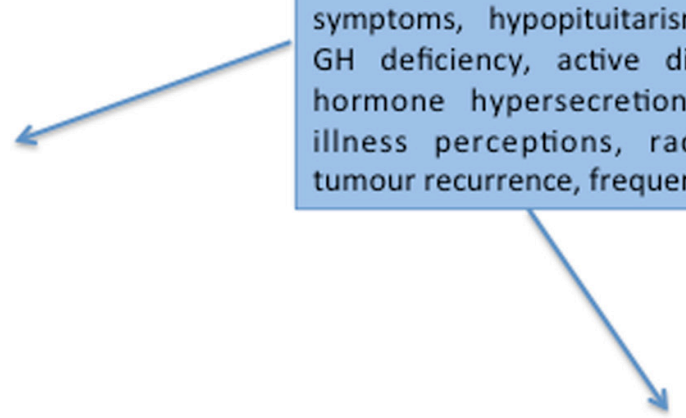

NFPA

Tumour recurrence, sleeping difficulties, fatigue/weakness, anxiety, less activity and low physical capacity, hypogonadism

\section{Figure 1}

Factors or markers most frequently described as determinants of impaired QoL in pituitary diseases include the following. Some are common to all pituitary adenomas (PA), while others are specific for each disease. 
Even though the mechanisms responsible for impaired QoL are multifactorial, persistent physical and psychological limitations due to irreversible effects of previous excessive hormone exposure and/or hormone deficiencies play an important role. It may also be affected by the psychological impact of suffering a pituitary disease that is a rare and chronic entity of low prevalence, and all that this means (for example, they perceive that nobody seems to know what the disease entails, once they are finally diagnosed after a long delay, despite long-standing physical and/or psychological complaints).

Apart from metabolic alterations and premature ageing related to hormonal dysfunction, psychiatric disorders and mental health issues are more frequent in population with pituitary adenomas than in the general population, but similar to patients with other non-pituitary endocrine disease $(4,5)$. Using the Structured Clinical Interview for Diagnostic and Statistical Manual of Mental Disorders version IV (DSM-IV) and the Diagnostic Criteria for Psychosomatic Research, patients with pituitary disease are more prone to have major depressive disorders (31\%), generalized anxiety disorders (29\%), irritable mood (51\%), demoralisation (36\%) and persistent somatisation (29\%), when compared to healthy subjects (5). In fact, compared to primary care patients, subjects with pituitary adenomas exhibit more subclinical or clinically relevant depression (25\% vs 40\%) (6). Current symptoms, the periodic necessity of injections or daily therapy, frequent medical follow-ups, or concomitant neuropsychological events, mainly depressive symptoms and anxiety as well as cognitive dysfunction may all affect personality, behaviour and lead to impaired QoL (7) (Fig. 1).

\section{How can QoL be measured?}

QoL is usually measured by questionnaires that may be generic or disease-generated, the latter also known as disease-specific. In both, the patients evaluate how they self-perceive their general health status through several possible ratings (i.e., yes or no; excellent, very good, good, slightly bad, bad; or always, most of the time, sometimes, rarely, never; or completely agree, moderately agree, neither agree or disagree, moderately disagree, completely disagree). Generic questionnaires have the advantage of being useful in any population, so comparisons can be made between patients with different diseases and normal healthy subjects (Table 1). Disease-generated or diseasespecific questionnaires are more sensitive in identifying dimensions most impaired by the disease (for instance,
Table 1 Some commonly used questionnaires to evaluate the health-related quality of life.

Generic questionnaires

- The Nottingham Health Profile (NHP)

- The Psychological General Well Being Scale (PGWBS)

- The EuroQol (including the EQ-5 Dimensions and EQ-Visual Analog Scale VAS)

- The Short Form 36 (SF-36)

Disease-generated or disease-specific questionnaires for pituitary adenomas

- AGHDA (Adult Growth Hormone Deficiency Assessment) or QLS-H (Questions on Life Satisfaction-Hypopituitarism) for growth hormone deficiency

- AcroQoL for acromegaly

- CushingQoL or the Tuebingen Cushing's disease Quality of Life Inventory (Tuebingen CD-25) for Cushing's syndrome

Some examples of domain-specific questionnaires AIMS2: Arthritis Impact Measurement Scale 2 BDI-II: Beck Depression Inventory II CSCL: Coping Strategies Check List FSFI: Female Sexual Function Index HADS: Hospital Anxiety and Depression Scale MFI: Multidimensional Fatigue Inventory

SQ: symptom questionnaire (anxiety, depression, somatic symptoms, anger/hostility)

improvement after treatment), but cannot be used in normal subjects or in other diseases. Additionally, there are 'domain-specific' questionnaires devoted to one problem (i.e., fatigability, pain, dyspnoea, sexual dysfunction, etc.), which can be applied to more than one illness with these problems, and are useful to compare the degree of impairment of that specific domain (Table 1).

If both a generic and a specific questionnaire are used simultaneously, it allows comparison with normative data from the generic instrument, as well as a more in-depth evaluation of the problems encountered in that specific disease, which is especially useful after a therapeutic intervention.

As for biochemical or any other parameters, QoL questionnaires have to be validated, including and fulfilling psychometric properties like feasibility, reliability, validity and sensitivity to change. Feasibility refers to how easy, convenient and/or acceptable it is to fill the questionnaire, and is assessed from the percentage of unanswered questions, which should not exceed $25 \%$ of the scored items. Reliability reflects internal consistency (expressed as a Cronbach coefficient $\alpha$, which should be greater than 0.70) and test-retest reliability, which refers to the questionnaires' capability to generate similar results over time, if the same clinical conditions are maintained; it may be expressed by an intraclass correlation coefficient which should be above 0.70 in all the dimensions. Validity refers to whether the instrument 
measures what it sets out to measure; cross-validity evaluates the capability of a questionnaire to evaluate QoL at a given time, while longitudinal validity is the capability to detect QoL changes over a period of time. Sensitivity to change, necessary in longitudinal studies, is the questionnaire's capability to detect changes in the patients' health when they actually occur. Furthermore, the percentage of patients who obtain the highest (ceiling effect) or lowest score (floor effect) have to be low, not to limit the questionnaire's capability to detect change across time or differences between groups of patients.

They also require validated translations, following standard methodology, when used in different cultural/ language settings, to allow comparison in multi-country studies (8). This methodology for the translation and cultural adaptation of a questionnaire into different languages has four steps (Fig. 2).

(i) First is the forward step, where two professional translators, native speakers of the target language and fluent in the original language, will separately translate the questionnaire, after which a consensus meeting will define the most accurate translation that will conceptually reflect the original meaning, in a colloquial and easy language.

(ii) Second is the backward step where a professional translator, native speaker of the original language and fluent in the target language, will translate the first intermediary version generated in the forward step, back into the original language, being as literal as possible.

(iii) This back translation (see Figure 2) is compared with the original version to detect any understanding problems; after correction, the second intermediary version is obtained, which is then presented to a group of some five patients with the specific disease the questionnaire was created for, to check comprehension and the degree of acceptability of the translated questionnaire; this is known as the cognitive debriefing step. All suggestions and comments raised during the interviews will be summarized, and changes and modifications will be assessed, in order to see whether any of them should be included in the translated version.

(iv) The last step is the finalisation, when the third intermediary version, including any change, will be
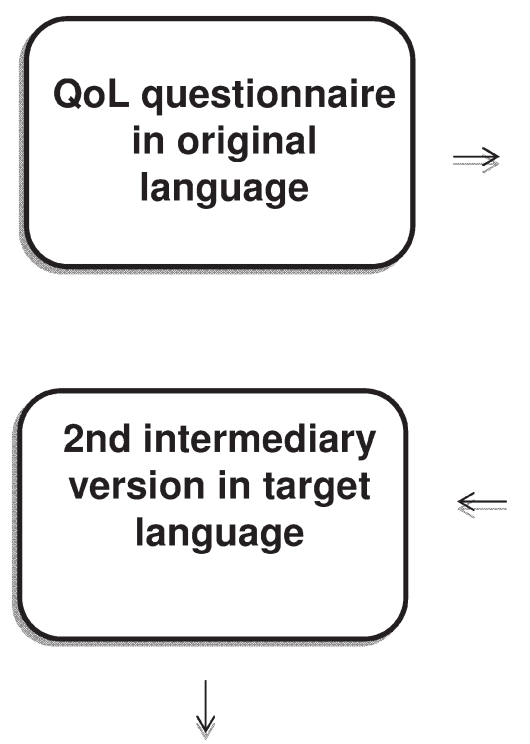

Presented to a group of patients $(n \sim 5)$ to check comprehension and degree of acceptability (cognitive debriefing)
Separate forward translation by 2 native speakers of target language and fluent in original language

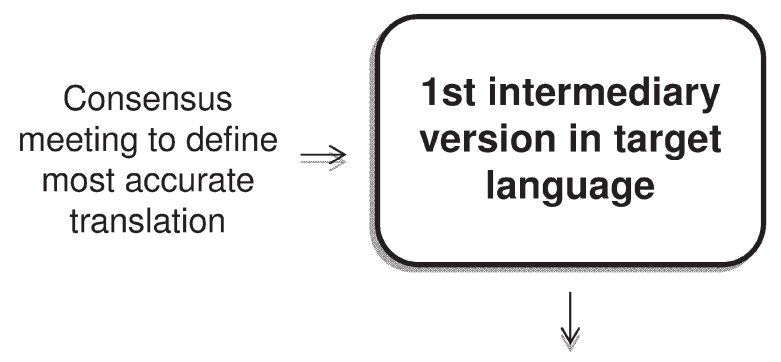

Backward step by a native-speaker professional translator of original language, and fluent in target language

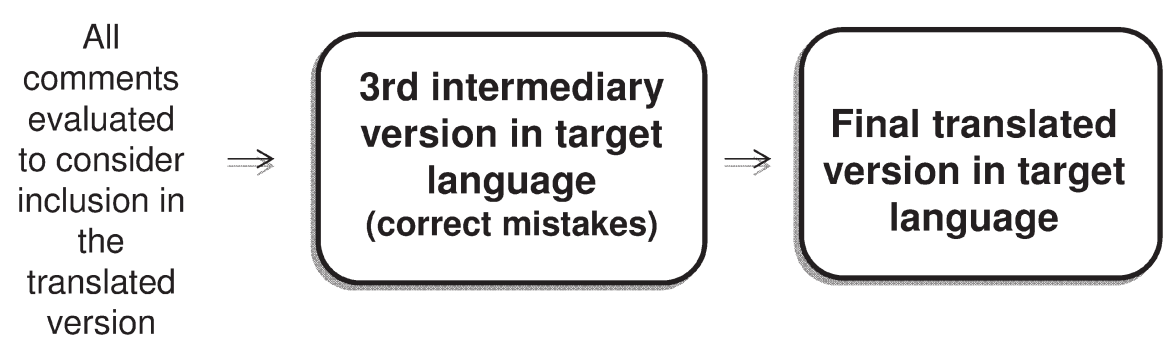

\section{Figure 2}

Translation and cultural adaptation procedures of a quality of life questionnaire. 
proofread by a native speaker of the target language to correct any mistake and to obtain the final translated version.

True practical validation however is completed when a large validation study on a new cohort has taken place and the factor analysis shows adequate psychometric properties.

\section{Utility of QoL evaluation}

Evaluation of QoL can highlight the patient's viewpoint on clinical aspects often not contemplated by clinicians, but of importance for the patient's everyday life (9). QoL assessment can therefore be considered an important outcome measure in clinical practice, and has been measured in patients with pituitary adenomas with untreated and treated disease. On the whole, QoL improves after therapy, but due to residual physical and psychological impairments, it often remains below normal even after successful treatment and endocrine 'cure', when compared to normative reference values or healthy controls $(7,10,11,12)$.

Since QoL reflects patient-related parameters, it is complementary to biochemical, radiological and other usual objective parameters used by clinicians in everyday clinical practice. Usually patients are pleased to be asked about problems and concerns that often affect them and may never have been verbalised. For clinicians, the information provided will make the knowledge on the patients' condition complete and sometimes bring to attention problems that otherwise pass unaware. Thus, it can only be beneficial to ask the patients on their QoL.

Self-administered questionnaires should be ideally completed in a quiet environment, by the patient himself/ herself, preferably before seeing the doctor or nurse, since answers may vary depending on the information perceived during the clinical visit. It also favours a better perception of high-quality medical care, may potentially improve patient-healthcare provider relationships and can be used to contribute to therapeutic decisions based on evidence and cost-efficacy. Furthermore, it may be used to select treatments not only able to attain biochemical control but also able to optimise QoL. Electronic versions of the questionnaires, which may be completed online, on tablets or Apps, are more and more frequent; however any migration from paper to online versions requires that the screen looks exactly like the paper version, or else a cognitive debriefing process as described for the translation procedure, to ensure equivalence.
QoL scores may be mapped to those of well-defined instruments used in pharmacoeconomy studies like the Short Form-6 Dimensions questionnaire (SF-6D) or EuroQoL-5 Dimensions (EQ-5D) scores, to derive costutility measurements at a group level. This allows a prediction model, for example in Cushing's syndrome (CS) using the CushingQoL questionnaire, which can be useful in health economy studies $(13,14,15)$.

\section{QoL tools for pituitary diseases}

There are currently specific questionnaires to evaluate QoL in hypopituitarism, acromegaly and Cushing's syndrome. Data on prolactinomas and non-functioning pituitary adenomas (NFPA) is more limited and only evaluable with generic questionnaires.

\section{Hypopituitarism (including growth hormone deficiency)}

QoL is an outcome measure in the evaluation of adults with growth hormone deficiency (AGHD) or hypopituitarism, after the unexpected observation of improvement in mood and vitality in pivotal trials with GH replacement, using generic questionnaires (16). Subsequently, two disease-specific questionnaires designed for patients with adult GHD were developed, namely the adult growth hormone deficiency assessment (AGHDA) questionnaire (17) and the Questions on Life Satisfaction-Hypopituitarism questionnaire (QLS-H) (18). Over the last 25 years, they have confirmed that patients with AGHD or hypopituitarism have impaired QoL, as well as decreased bone and muscle mass, increased fat mass, reduced physical performance, an unfavourable lipid profile and increased insulin resistance (19). This is especially so if the deficiency appeared in adult life rather than in childhood, since these younger subjects are more capable to adapt to their disabilities, with less impact on their future everyday activities.

The AGHDA questionnaire includes questions on dimensions related to dislike of body image, low energy, low capacity of sexual arousal and socializing, tenseness, poor concentration, memory, lack of self-confidence and increased irritability (20). The least impaired dimensions (problems with socializing and tenseness) tend to normalize earlier after initiating substitution therapy with recombinant human GH (rhGH) than self-confidence, tiredness and dissatisfaction with physical activity during leisure time, while the most affected dimensions 
(memory and concentration) are the last in improving (21). Additionally, rhGH-replaced AGHD patients reduce the use of healthcare resources (visits to doctor, days in hospital, sick leave and assistance with daily activities). The degree of improvement in QoL with rhGH replacement has been shown to be proportional to the baseline deviation from normality, so that those individuals with worse QoL at baseline tend to show the greatest improvement after treatment. Energy and emotional reactions tend to improve during the first 6 months (but may occur later) and remain so up to 10 years later (19), so that treated patients do not differ from matched controls anymore. Although challenged by some, in countries like the UK, a bad QoL score on AGHDA ( $>11)$ is a criterion to initiate substitution treatment with rhGH in AGHD and to maintain it (since an improvement of at least 7 points on the AGHDA score is to be evidenced) ((22); https:// www.nice.org.uk/guidance/TA64/chapter/1-guidance: Human growth hormone (somatrophin) in adults with growth hormone deficiency. Technology appraisal guidance (TA64) Published date: 27 August 2003; accessed December 31, 2016).

The QLS-H questionnaire has the advantage of weighting each item by the individual patient. Patients are first asked how important each item is to them and later how satisfied they are with each item $(18,19)$. The disadvantage in relation to AGHDA is that the score calculation is more complex and usually requires a computer programme. Nevertheless, results from over 1500 patients included in a post-marketing surveillance trial have shown with this QLS-H questionnaire how impaired QoL improved after substitution therapy with rhGH, in GHD of any aetiology, and persisted a decade after initiating the treatment (19). A greater QoL improvement was observed in those who were not depressed, lived in Europe (as compared to the US), had poorer initial Z-scores (i.e., worse QoL), had a lower body mass index (BMI) at entry, and had no impaired vision (19). If GH treatment is discontinued for several months, emotional reactions, well-being and tiredness worsen, especially in younger patients, all of which may negatively affect $\operatorname{QoL}(23,24)$.

QoL is also impaired by the presence of postoperative ACTH insufficiency (25). Initial hydrocortisone treatment is followed by great symptomatic improvement, but chronic hydrocortisone substitution is shown to be associated with lower QoL, perhaps due to high, nonphysiological glucocorticoid doses (26).

Gonadotrophin deficiency leading to hypogonadism also impairs QoL compared to age-standardized general population $(27,28,29,30)$. In males, low testosterone is associated with physical impairment (i.e., reduced muscle strength or osteoporosis), as well as psychological disturbances (depression, anxiety and sexual dysfunctions like decreased libido), often associated to infertility which is another common complaint, all of which negatively impact on QoL (29). Using the generic SF-36 questionnaire, more problems in the areas of role-physical, vitality, physical functioning, general health and role-emotional were observed in hypogonadal patients when compared to healthy controls (25). After the replacement therapy with testosterone, vitality, physical role, general health and emotional role parameters improved, but were still below the reference values.

Mechanisms by which AGHD and hypopituitarism determine QoL impairment are multifactorial, in parallel to the widespread physiological actions of $\mathrm{GH}$, gonadal steroids and hydrocortisone. Abnormal body composition, decreased exercise capacity and muscle strength, decreased body water related to fatigue, metabolic disturbances and possible neuroendocrine effects in the central nervous system, all may negatively impact on physical capacity, cognitive functioning and psychological well-being. This multiplicity of actions is further supported by the common finding of no correlation between improvements in QoL and biochemical markers used to evaluate hormone replacement, metabolic parameters or body composition indices in treated AGHD or hypopituitarism.

\section{Acromegaly}

Incorporating QoL measurements in the regular clinical follow-up of patients with acromegaly shows it is often still impaired, even after successful treatment. Factors affecting patients' well-being are multidimensional (physical, psychological, social, demographic or related to treatments). If the consequences of acromegaly which negatively impact on patients' daily living are identified, or the patients' main needs during management of the disease are relevant, they may be approached and measures introduced to improve them.

The use of the AcroQoL questionnaire and simultaneous generic questionnaires with normative data has confirmed that QoL is impaired in acromegaly, especially in active disease (31). AcroQoL scores can be analysed globally (22 questions with a 5-point Likert scale for each item), or separating physical (8 items) and psychological domains (14 items, subdivided into appearance and personal relations sub-domains, with 7 items each). Comparable results are reported in all available languages (32); the dimension most affected is 
appearance; this would suggest that an earlier diagnosis before irreversible morphological changes occur would probably be beneficial. In contrast, the least impacted area is the personal relations sub-domain of the psychological dimension (32).

Successful therapy is usually followed by improvement in the AcroQoL score, but disease control may not normalize QoL scores completely, as evidenced with generic questionnaires with normative data. When comparing QoL in different pituitary patients with generic questionnaires, acromegalic patients score worse for physical ability and functioning and bodily pain than non-functioning pituitary adenomas (NFPA) or prolactinomas, and the presence of hypopituitarism further impairs their well-being and QoL (33).

Increased psychopathology (mainly anxiety and depression), maladaptative personality traits or less effective coping strategies have been described in patients with controlled acromegaly, which in turn may affect cognition and QoL $(2,33,34,35,36)$ (Fig. 1). They tend to be more harm-avoidant and neurotic with a high social conformity $(35,36)$, show a reduction in novelty-seeking behaviour, and are less impulsive than patients with other diseases like NFPA. This increased anxiety may not only affect QoL, but also affect treatment adherence and patient-physician contact.

A greater sensitivity of the physical dimension of the AcroQoL questionnaire than circulating IGF-I concentration was observed in treated acromegalic patients with a normal circulating IGF-I on long-acting somatostatin analogues, who reported improvement in QoL after adding pegvisomant treatment. This was interpreted as indicative that 'normal' circulating GH and IGF-I may not reflect 'control' or 'cure' in all body tissues. In fact, despite no change in circulating IGF-I levels, patients perceived improvement in QoL scores and subjective well-being, which was correlated with the physical domain of AcroQoL and loss of body water and weight, suggesting that their muscles were less exposed to excessive GH/IGF after adding pegvisomant (37).

Apart from the disease activity, worse QoL has been observed if patients complain of persistent headache or musculoskeletal pain $(38,39)$. When comparing disease control after surgery or due to on-going medical therapy, QoL scores are usually better when no chronic treatment is required (40). The chronic nature of acromegaly, requiring on-going treatment and periodic follow-ups, even in the so-called 'controlled' or 'cured' cases, probably contributes to their more negative illness perceptions and QoL, compared to patient groups with acute pain or vestibular schwannoma (35).

Having undergone treatment with radiotherapy is also associated with worse QoL scores in acromegaly, although it is unknown whether this is due to a more aggressive disease requiring multimodal treatment for control, or due to the irradiation effect itself $(41,42)$. Other parameters identified as markers of worse QoL in acromegaly are being older $(10,43)$, being female rather than male (44), having coexisting diabetes mellitus (43), having a higher BMI (10), having a longer disease duration (10), or becoming GH-deficient after the treatment for acromegaly, usually induced by prior radiotherapy $(43,45)$.

A meaningful change in the AcroQoL score after therapy has been investigated using a distributionbased estimate of the half-standard deviation method, as recommended by the Food and Drug Administration (FDA) Patient-Reported Outcomes guidance for longitudinal studies $(46,47)$. Results from a large phase 3 clinical trial comparing baseline and Month 12 data after monthly injections of two somatostatin analogues, namely pasireotide LAR $(n=176)$ and octreotide LAR $(n=182)$, established that a change in the AcroQoL total score of \pm 9.8 (which represented $50 \%$ of the baseline s.D. of AcroQoL score - 19.6) could be considered meaningful (minimum important difference) (46). Biochemical control was considered if GH was $<2.5 \mu \mathrm{g} / \mathrm{L}$ and IGF- 1 was normal at Month 12. This pattern was consistent for both the AcroQoL physical and psychological subscales.

\section{Cushing's disease}

Cushing's disease (CD) and Cushing's syndrome (CS) of any aetiology (adrenal, pituitary or ectopic) present chronic hypercortisolism. It is now evident that this glucocorticoid excess exerts irreversible glucocorticoid toxicity on different brain structures and determines persistent impaired QoL, sustained psychological dysfunction and structural brain abnormalities, despite endocrine remission (48). All causes (adrenal, pituitary or ectopic) affect QoL in a similar way. The additional persistent physical morbidity (including increased risk for cardiovascular events, fatigability related to myopathy, and bone fragility) contribute negatively to the patient's well-being and consequently to their QoL. Results using both generic questionnaires like the SF-36 survey and the derived SF-12, or the Hospital Anxiety and Depression Scale (HADS), and both available 
disease-specific questionnaires, the CushingQoL $(49,50$, 51 ) and the Tuebingen CD-25 questionnaires (52), have shown this persistent impairment. Successful treatment does improve scores, but normalisation often does not occur, even many years after control of hypercortisolism.

CushingQoL consists of 12 questions with a 5-option Likert scale answer, which was described as unidimensional (53). Recently however two subscales (psychosocial issues and physical problems) were identified, which showed adequate model fit. Data were obtained from patients in remission from CS $(n=341)$ recruited from the Cushing's Syndrome Research Foundation's email lists; they completed the CushingQoL questionnaire and a short demographics survey (54). Regardless of the scoring solution used, it was concluded that CushingQoL had proven to be a valuable resource for assessing healthrelated QoL in patients with CS.

The brain volume decreases in CS, especially in active hypercortisolism and in patients diagnosed at an older age, which is thought to be related to less brain plasticity compared to younger subjects, although other factors may also be involved, i.e., longer disease duration and exposure to hypercortisolism $(48,55)$. Interestingly, a positive correlation was found between the right cerebellar cortex volume and the CushingQoL scores.

Depression, anxiety and cognitive dysfunction are common in CS, especially in the active phase, although the so-called 'cured' patients still complain of a lower general well-being, more anxiety and depression, and impaired QoL when compared to matched healthy controls $(49,56$, $57,58)$. Furthermore, after successful treatment, it often takes several months or even more than 1 year to perceive improvements. Being aware of this time course is important both for endocrine specialists and patients; the immediate postoperative phase can be very troublesome in CS due to a 'glucocorticoid deprivation phase', with more pain and devastating fatigability, which often leads to depression and a low QoL perception. Glucocorticoid dose has to be tapered after successful surgery, but this is challenging for some patients who just cannot tolerate dose reduction, even several weeks or months after the surgery. Even in the long-term management of CS, being aware of these changing situations does help patients conform, with the hope of final improvement (5). Common complaints like cognitive impairments and psychiatric disorders, as well as periodic follow-ups to evaluate pituitary function and detect possible recurrences of hypercortisolism, put extra stress on these CS patients, which in turn worsens psychological issues and often leads to a bad QoL.
The minimal important difference in the CushingQoL score to be clinically meaningful was found to be 10.1, based on the half-standard deviation distribution method (51) as recommended by the FDA and other regulatory agencies in the USA and Europe, allowing comparison of different treatments on the patient's outcome. This longitudinal study confirmed CushingQoL as a reliable, valid and responsive (good test-retest reliability and sensitivity to change) questionnaire to assess QoL and other relevant clinical outcomes in adults with CD.

Although obesity is a characteristic of CS, differences in QoL were identified between both diseases, using the SF-36 survey and a symptom questionnaire (59). Obese patients, mostly women with a mean average age between 40 and 50 years, had better QoL in the mean physical component summary (PCS) score, but worse mean mental component summary (MCS) than CS patients. The presence of more CS symptoms worsened the PCS and MCS scores, while obese patients surprisingly showed worse mental health scores than the CS population. BMI correlated with PCS in obesity, but not in CS, and was not associated with MCS in either group.

The Tuebingen CD-25 questionnaire showed improvement after successful surgery in $17 \mathrm{CD}$ patients (52); three-quarters of the patients had impaired QoL preoperatively, but only one-third of them had impaired QoL after successful surgery. A better postoperative QoL was observed in the presence of less comorbidities $(\leq 2)$ and greater morning cortisol decrease. Predictors for postoperative improvement in QoL were greater preoperative QoL impairment and a younger age, as also reported using the CushingQoL questionnaire (60). Other predictors of impaired QoL are having experienced a long delay until a correct diagnosis of CS was obtained (61) or having seen more physicians before a correct diagnosis of CS was made $(62,63)$. Whether this means that patients who experience greater discomfort demand more physician visits or it simply indicates a longer duration of symptoms is not yet clear. In comparison, patients who are treated by physicians who specialize in CS report better QoL. Since a bad QoL can influence working capacity, it may have major economic consequences for patients and their families $(62,63)$.

Similar results with the SF-36 and Tuebingen CD-25 questionnaires were also reported after bilateral adrenalectomy in 50 patients with CS, most of which were followed for a median of 11 years (64). While comorbidities like hypertension, diabetes mellitus, osteoporosis, muscle weakness, cushingoid phenotype 
and menstrual irregularity improved after surgery, QoL was still impaired in $45 \%$ of female and $16.7 \%$ of male patients, when compared with a healthy population (64).

A specific nursing interventional programme for patients with CS demonstrated an improvement in physical activity, healthy lifestyle habits, adherence to therapy, sleep patterns, and a reduction in pain level and in the use of health resources, all influencing QoL. As also observed in hypopituitarism, those patients with the greatest impairment in their QoL benefitted most from the educational intervention (65).

The effect of sequential stepwise medical therapy on QoL and recovery of physiological salivary and plasma cortisol diurnal rhythm was investigated in 17 patients with active hypercortisolism (66). Somatostatin analogue pasireotide treatment was followed by the dopamine agonist cabergoline, and later the adrenal-blocking agent ketoconazole was added if normal urinary free cortisol (UFC) was not reached. The CushingQoL, Nottingham Health Profile (NHP), HADS, Multidimensional Fatigue Inventory (MFI) and RAND-36 instruments were evaluated. The RAND-36 includes the same set of items as SF-36 and were both developed in the Medical Outcomes Study, but scoring of the general health and pain scales differ (67). After 80 days, 15/17 (88\%) patients had normalized UFC. Subsequently, patients continued medical therapy for 1 year or underwent surgery. Cortisol diurnal rhythm was preserved at baseline in 5/17 patients and in another 6/12 with disturbed baseline rhythm; recovery occurred but was not correlated with QoL. It was impaired in most subscales $(18 / 20)$ in CD patients compared to literaturederived controls. At Day 80, patients reported more pain, interpreted as a reflection of steroid-withdrawal, but QoL did not improve or deteriorate. The baseline CushingQoL scores (around 50) tended to improve after 1 year of remission in 3 patients who continued medical therapy (to over 75), reflecting how long it takes for QoL to recover, despite control of hypercortisolism.

Using the Beck Depression Inventory II (BDI-II), the SF-36 and the Multidimensional Body-Self Relations Questionnaire (MBSRQ), it was found that QoL in the general health category and perception of body image were worse in 40 patients with $\mathrm{CD}$ who underwent transsphenoidal surgery, compared to 40 healthy controls (68). In contrast with several other studies however no differences in depression scores were found between CD patients globally and controls. However in CD patients without remission, depression was more prevalent than in both CD patients with remission and healthy subjects. Additionally, physical functioning, bodily pain and general health scores of the SF-36 questionnaire in CD patients without remission were also worse than those in CD patients with remission and healthy subjects.

A higher prevalence of 'maladaptive' personality traits in CS patients even after long-term cure may affect their everyday QoL (69). They appear to perceive that they are characterized by 'unpleasant' increased anxiety traits (pessimism, neuroticism, shyness with strangers and low extraversion), and try to answer in a rather 'pleasant' (or socially desirable) way.

A large study from the Netherlands included 123 patients with CS with remission for a mean of $13.3 \pm 10.4$ years, on average in their 50 s, $86 \%$ women, and $80 \%$ of pituitary origin. Seven validated questionnaires were presented to these patients and compared with an age- and sex-matched control group $(n=105)(70)$. These instruments were RAND-36, HADS and the Checklist Individual Strength Questionnaire (CIS) designed to measure several aspects of fatigue; the Cognitive Failures Questionnaire (CFQ) to detect everyday mistakes and problems regarding perception, memory, motor function and orientation; the Appearance Self-Esteem (ASE), part of the Self-report State Self-Esteem Scale comprising satisfaction with one's appearance; the CushingQoL and NHP questionnaires; and an employment status and selfreported comorbidity questionnaire regarding current employment, number of working hours per week, current sick leave and inability to work; and a checklist mentioning 16 common diseases like diabetes mellitus, cardiovascular disease, hypertension and psychiatric problems.

QoL was worse on practically all dimensions of questionnaires compared with the control group, except for patients in remission of pituitary CS without hormonal deficiencies, who only showed impaired QoL on $50 \%$ of the dimensions evaluated. No difference between patients with remission of adrenal and pituitary CS were observed on QoL, but women (vs men) and a shorter duration of remission did influence QoL negatively. So again, it was concluded that QoL was still impaired in patients with long-term remission of CS, regardless of aetiology (i.e., pituitary, adrenal, or ectopic ACTH secretion), presence of hormonal deficiencies and treatment strategies, suggesting that hypercortisolism and not the location of the tumour determines QoL impairment $(62,70)$.

Since CS has considerable psychological and physical consequences, it is important to prepare the patient so he/she is aware and can try to cope with the aftermath, a first step to facilitate improvement in the long term. Most patients do not feel much better after treatment, and some even feel worse; this is most frequently related to fatigue, 
decreased muscle strength and weakness, weight gain especially around the abdomen, forgetfulness, trouble sleeping, depression and anxiety $(62,63)$.

Encouragement to take care of themselves, to take the reigns of their lives, with new hobbies or challenges within their capacities next to recommendations on a healthy diet, regular exercise and being regular with their prescribed treatment can help, as well as support from friends and family. A message of hope in the sense that despite many changes after CS it is still possible to be happy if one works at it is worth remembering (62).

\section{Prolactinoma}

Since no disease-specific questionnaires are available for prolactinomas up to now, less interest has been shown in evaluating QoL in this disease $(7,71,72)$. The affected patients complain of more stress, psychological distress and less well-being (5). In the systematic review by Andela (7), spider plots comparing the different domains of the SF-36 questionnaire were compared for the different dimensions, namely physical functioning, mental health, emotional role, social functioning, vitality, general health, pain and physical role. All domains tended to improve after the treatment; in prolactinomas as well as in NFPA, results were very close to normative scores, which was not the case in acromegaly and especially in CS, pointing to the persistent deleterious effect of prior exposure to excessive GH/IGF-1 and hypercortisolism. Other generic or domain-specific questionnaires (SF-36, HADS, MFI and NHP) have been used in prolactinoma patients and the results are expressed in Z-scores (or standard deviation scores), thus accounting for age and gender, so results can be compared with other reference populations. Again, prolactinomas and NFPA showed less impairment than acromegaly and CS for physical ability and functioning and less bodily pain, but concomitant hypopituitarism further impaired multiple aspects of QoL (11).

Nevertheless, despite clinical control of tumour size and prolactin levels, poor QoL may persist, especially in women, with worse scores in physical problems, vitality, emotional aspects and social isolation compared to control subjects, independent of prolactin levels, current or previous treatment with dopamine agonists, and dose or specific drug used $(71,72,73)$.

An important feature in prolactinomas, which impairs QoL, is gonadal dysfunction, with complaints like decreased libido, erectile dysfunction and poor seminal fluid quality in men and amenorrhoea, galactorrhoea, vaginal dryness leading to dyspareunia and decreased libido in women, all of which favour infertility. This QoL impairment is worse in women (73). Additionally, sleeping difficulties namely increased slow-wave sleep compared to healthy controls may also impair QoL in prolactinoma patients $(6,74)$.

\section{Non-functioning pituitary adenomas}

As with prolactinomas, there are currently no specific questionnaires to evaluate QoL in patients with NFPA. Although most reports on QoL using generic questionnaires in NFPA describe a low QoL after treatment $(7,11,41,75$, 76), there are also descriptions of normalization of QoL, after successful treatment, attaining scores comparable to those seen in a healthy population $(77,78)$. As already mentioned, compared to that of other pituitary adenoma patients, QoL of NFPA patients was similar to that of patients treated for prolactinoma, and better than that of patients diagnosed with CD and acromegaly $(11,39$, $79,80)$.

Female gender and older age are also determinants of more QoL impairment in NFPA, as observed in normal population and other pituitary diseases (CD and acromegaly) $(11,81)$. NFPA patients tend to be older than patients with other pituitary adenomas and report impairments in both physical and mental measures. Recent data observed how female NFPA patients had physical and emotional complaints, reduced energy and poorer health perception in comparison to their male counterparts (77). A determinant negative factor for QoL in these NFPA is visual dysfunction, a common symptom in these often large macroadenomas $(7,81)$; residual visual deficits have been associated with reduced interest in leisure activities or hobbies (76). The presence of concomitant diabetes mellitus, obesity, depression and hypopituitarism all have a strong negative impact on overall QoL (81). If hypogonadism is present, it determines worse social life and reduced daily activity compared to those patients with NFPA who are not hypogonadal or are on correct hormone replacement (76, 77). GH deficiency determines more bodily pain, and worse mental health and general health perception compared to GH-sufficient patients or patients on substitution therapy with GH (77).

Prior radiotherapy reportedly is followed by impaired mental health and less energy levels, without affecting the general health perception $(77,78)$. Abnormal scores in energy, physical ability and anxiety have also been 
described in patients with NFPA who experience a tumour recurrence $(77,81)$.

A bad quality of sleep (reduced sleep efficiency, less rapid eye movement sleep and increased daytime somnolence) also determine poor QoL in these patients, and is often associated with fatigue, low motivation, more awakening at night and less activity during the day $(11,75)$.

\section{Conclusion}

QoL evaluated with questionnaires is impaired in patients with pituitary diseases, especially in the active phase, and more severely in acromegaly and hypercortisolism than in prolactinomas and NFPA. The presence of additional pituitary deficiencies tends to worsen QoL further. Despite endocrine 'cure', QoL often remains below reference values; this is a matter of concern for many patients, as recently evidenced with the Leiden Bother and Needs Questionnaire for patients with pituitary disease (the LBNQ-Pituitary). This tool can individually identify their needs for support and lead to efficient assessment in clinical practice, optimal patient care and improvement in their QoL (82). The challenge for the future is how to improve outcome of pituitary patients, so that they can be considered completely healthy, both physically and mentally. Establishing the relationship between QoL dimensions and changes in hormonal status is the key to understand the relationship between biochemical and clinical (QoL) changes. To improve long-term prognosis, and offer a realistic expectation with respect to the results of treatment, awareness on the lack of complete normalization of QoL and cognitive function outcome is worth considering.

\section{Declaration of interest}

The authors declare that there is no conflict of interest that could be perceived as prejudicing the impartiality of this review.

\section{Funding}

This research did not receive any specific grant from any funding agency in the public, commercial or not-for-profit sector.

\section{References}

1 Romijn JA. The chronic syndromes after previous treatment of pituitary tumours. Nature Reviews Endocrinology 201612 547-556. (doi:10.1038/nrendo.2016.84)

2 Webb SM. Coping with 'cured' pituitary tumors. Nature Reviews Endocrinology 20117 251-252. (doi:10.1038/nrendo.2011.39)
3 Schipper H, Clinch JJ \& Olweny CLM. Quality of life studies: definitions and conceptual issues. In Quality of Life Assessments in Clinical Trials, p 16. Ed B Spilker. New York: Raven Press Ltd, 1990.

4 Flitsch J, Spitzner S \& Lüdecke DK. Emotional disorders in patients with different types of pituitary adenomas and factors affecting the diagnosis process. Experimental and Clinical Endocrinology and Diabetes 2000108 480-485. (doi:10.1055/s-2000-8144)

5 Sonino N, Ruini C, Navarrini C, Ottolini F, Sirri L, Paoletta A, Fallo F, Boscaro M \& Fava GA. Psychosocial impairment in patients treated for pituitary disease: a controlled study. Clinical Endocrinology 200767 719-726. (doi:10.1111/j.1365-2265.2007.02951.x)

6 Leistner SM, Klotsche J, Dimopoulou C, Athanasoulia AP, RoemmlerZehrer J, Pieper L, Schopohl J, Wittchen HU, Stalla GK, Fulda S et al. Reduced sleep quality and depression associate with decreased quality of life in patients with pituitary adenomas. European Journal of Endocrinology 2015172 733-743. (doi:10.1530/EJE-14-0941)

7 Andela CD, Scharloo M, Pereira AM, Kaptein AA \& Biermasz NR. Quality of life (QoL) impairments in patients with a pituitary adenoma: a systematic review of QoL studies. Pituitary 201518 752-776. (doi:10.1007/s11102-015-0636-7)

8 Herdman M, Fox-Rushby J \& Badia X. A model of equivalence in the cultural adaptation of HRQoL instruments: the Universalist approach. Quality of Life Research 19987 323-335. (doi:10.1023/ A:1008846618880)

9 Webb SM \& Badia X. Quality of life in acromegaly. Neuroendocrinology 2016103 106-111. (doi:10.1159/000375451)

10 Biermasz NR, van Thiel SW, Pereira AM, Hoftijzer HC, van Hemert AM, Smit JW, Romijn JA \& Roelfsema F. Decreased quality of life in patients with acromegaly despite long-term cure of growth hormone excess. Journal of Clinical Endocrinology and Metabolism 200489 5369-5376. (doi:10.1210/jc.2004-0669)

11 van der Klaauw AA, Kars M, Biermasz NR, Roelfsema F, Dekkers OM, Corssmit EP, van Aken MO, Havekes B, Pereira AM, Pijl $\mathrm{H}$ et al. Disease-specific impairments in quality of life during long-term follow up of patients with different pituitary adenomas. Clinical Endocrinology 200869 775-784. (doi:10.1111/j.13652265.2008.03288.x)

12 van Aken MO, Pereira AM, Biermasz NR, van Thiel SW, Hoftijzer HC, Smit JW, Roelfsema F, Lamberts SW \& Romijn JA. Quality of life in patients after long-term biochemical cure of Cushing's disease. Journal of Clinical Endocrinology and Metabolism 200590 3279-3286. (doi:10.1210/jc.2004-1375)

13 Gray LC, Goldsmith HF \& Livieratos BB. Individual and contextual social-status contributions to psychological well-being. Sociology and Social Research 198368 78-95.

14 Dolan P. Modelling valuations for EuroQol health states. Medical Care 199735 1095-1108. (doi:10.1097/00005650-199711000-00002)

15 Badia X, Herdman M \& Schiaffino A. A determining correspondence between scores on the EQ-5D 'thermometer' and a 5-point categorical rating scale. Medical Care 199937 671-677. (doi:10.1097/00005650199907000-00007)

16 Wiren L, Bengtsson BA \& Johannsson G. Beneficial effects of longterm GH replacement therapy on quality of life in adults with GH deficiency. Clinical Endocrinology 199848 613-620. (doi:10.1046/ j.1365-2265.1998.00462.x)

17 McKenna SP, Doward LC, Alonso J, Kohlmann T, Niero M, Prieto L \& Wiren L. The QoL.AGHDA: an instrument for the assessment of quality of life in adults with growth hormone deficiency. Quality of Life Research 19998 373-383. (doi:10.1023/A:1008987922774)

18 Blum WF, Shavrikova EP, Edwards DJ, Rosilio M, Hartman ML, Marín F, Valle D, van der Lely AJ, Attanasio AF, Strasburger CJ et al. Decreased quality of life in adult patients with growth hormone deficiency compared with general populations using the new, validated, self-weighted questionnaire, questions on life satisfaction hypopituitarism module. Journal of Clinical Endocrinology and Metabolism 200388 4158-4167. (doi:10.1210/jc.2002-021792) 
19 Mo D, Blum WF, Rosilio M, Webb SM, Qi R \& Strasburger CJ. Ten-year change in quality of life in adults on growth hormone replacement for growth hormone deficiency: an analysis of the hypopituitary control and complications study. Journal of Clinical Endocrinology and Metabolism 201499 4581-4588. (doi:10.1210/jc.2014-2892)

20 Feldt-Rasmussen U, Brabant G, Maiter D, Jonsson B, Toogood A, Koltowska-Haggstrom M, Rasmussen AK, Buchfelder M, Saller B \& Biller BM. Response to GH treatment in adult GH deficiency is predicted by gender, age, and IGF1 SDS but not by stimulated GH-peak. European Journal of Endocrinology 2013168 733-743. (doi:10.1530/EJE-13-0005)

21 Koltowska-Häggström M, Mattsson AF \& Shalet SM. Assessment of quality of life in adult patients with GH deficiency: KIMS contribution to clinical practice and pharmacoeconomic evaluations. European Journal of Endocrinology 2009161 (Supplement 1) S51-S64. (doi:10.1530/eje-09-0266)

22 Philip S, Howat I, Carson M, Booth A, Campbell K, Grant D, Patterson C, Schofield C, Bevan J, Patrick A et al. An audit of growth hormone replacement for GH-deficient adults in Scotland. Clinical Endocrinology 201378 571-576. (doi:10.1111/cen.12017)

23 Filipsson Nyström H, Barbosa EJL, Nilsson AG, Norrman L, Ragnarsson O \& Johannsson G. Discontinuing long-term GH replacement therapy - a randomized, placebo-controlled crossover trial in adult GH deficiency. Journal of Clinical Endocrinology and Metabolism 201297 3185-3195. (doi:10.1210/jc.2012-2006)

24 Appelman-Dijkstra NA, Rijndorp M, Biermasz NR, Dekkers OM $\&$ Pereira AM. Effects of discontinuation of growth hormone replacement in adult GH-deficient patients: a cohort study and a systematic review of the literature. European Journal of Endocrinology 2016174 705-716. (doi:10.1530/EJE-15-1086)

25 Ragnarsson O, Mattsson AF \& Monson JP. The relationship between glucocorticoid replacement and quality of life in 2737 hypopituitary patients. European Journal of Endocrinology 2014171 571-579. (doi:10.1530/EJE-14-0397)

26 Hahner S, Loeffler M, Fassnacht M, Weismann D, Koschker AC, Quinkler M, Decker O, Arlt W \& Allolio B. Impaired subjective health status in 256 patients with adrenal insufficiency on standard therapy based on cross-sectional analysis. Journal of Clinical Endocrinology and Metabolism 200792 3912-3922. (doi:10.1210/jc.2007-0685)

27 Aydogan U, Aydogdu A, Akbulut H, Sonmez A, Yuksel S, Basaran Y, Uzun O, Bolu E \& Saglam K. Increased frequency of anxiety, depression, quality of life and sexual life in young hypogonadotropic hypogonadal males and impacts of testosterone replacement therapy on these conditions. Endocrine Journal 201259 1099-1105. (doi:10.1507/endocrj.EJ12-0134)

28 Lasaite L, Ceponis J, Preiksa RT \& Zilaitiene B. Impaired emotional state, quality of life and cognitive functions in young hypogonadal men. Andrologia 201446 1107-1112. (doi:10.1111/and.12199)

29 Shiraishi K, Oka S \& Matsuyama H. Assessment of quality of life during gonadotrophin treatment for male hypogonadotrophic hypogonadism. Clinical Endocrinology 201481 259-265. (doi:10.1111/cen.12435)

30 Varimo T, Hero M, Laitinen EM, Sintonen H \& Raivio T. Health-related quality of life in male patients with congenital hypogonadotropic hypogonadism. Clinical Endocrinology 201583 141-143. (doi:10.1111/cen.12701)

31 Webb SM, Prieto L, Badia X, Albareda M, Catalá M, Gaztambide S, Lucas T, Páramo C, Picó A, Lucas A et al. Acromegaly Quality of Life Questionnaire (ACROQOL) a new health-related quality of life questionnaire for patients with acromegaly: development and psychometric properties. Clinical Endocrinology 200257 251-258. (doi:10.1046/j.1365-2265.2002.01597.x)

32 Webb SM, Resmini E, Santos A \& Badia X. Quality of life in acromegaly and growth hormone deficiency. In Growth Hormone Clinics in Endocrinology and Metabolism, pp 237-250. Eds K Ho \& D LeRoith. New York: Humana Press, 2011. (doi:10.1007/978-160761-317-6_12)
33 Crespo I, Valassi E \& Webb SM. Update on quality of life in patients with acromegaly. Pituitary 201620 185-188. (doi:10.1007/s11102016-0761-y)

34 Tiemensma J, Kaptein AA, Pereira AM, Smit JW, Romijn JA \& Biermasz NR. Coping strategies in patients after treatment for functioning or nonfunctioning pituitary adenomas. Journal of Clinical Endocrinology and Metabolism 201196 964-971. (doi:10.1210/jc.2010-2490)

35 Tiemensma J, Kaptein AA, Pereira AM, Smit JW, Romijn JA \& Biermasz NR. Affected illness perceptions and the association with impaired quality of life in patients with long-term remission of acromegaly. Journal of Clinical Endocrinology and Metabolism 201196 3550-3558. (doi:10.1210/jc.2011-1645)

36 Sievers C, Ising M, Pfister H, Dimopoulou C, Schneider HJ, Roemmler J, Schopohl J \& Stalla GK. Personality in patients with pituitary adenomas is characterized by increased anxiety related traits: comparison of 70 Acromegalic patients to patients with non-functioning pituitary adenomas and age and gender matched controls. European Journal of Endocrinology 2009160 367-373. (doi:10.1530/EJE-08-0896)

37 Neggers SJ, van Aken MO, de Herder WW, Feelders RA, Janssen JA, Badia X, Webb SM \& van der Lely AJ.Quality of life in acromegalic patients during long-term somatostatin analog treatment with and without pegvisomant. Journal of Clinical Endocrinology and Metabolism 200893 3853-3859. (doi:10.1210/jc.2008-0669)

38 Mangupli R, Camperos P \& Webb SM. Biochemical and quality of life responses to octreotide-LAR in acromegaly. Pituitary 201417 495-499. (doi:10.1007/s11102-013-0533-x)

39 Miller A, Doll H, David J \& Wass JAH. Impact of musculoskeletal disease on quality of life in long-standing acromegaly. European Journal of Endocrinology $2008 \mathbf{1 5 8}$ 587-593. (doi:10.1530/EJE-07-0838)

40 Matta MP, Couture E, Cazals L, Vezzosi D, Bennet A \& Caron P. Impaired quality of life of patients with acromegaly: control of $\mathrm{GH} /$ IGF-I excess improves psychological subscale appearance. European Journal of Endocrinology 2008158 305-310. (doi:10.1530/EJE-07-0697)

41 Johnson MD, Woodburn CJ \& Vance ML. Quality of life in patients with a pituitary adenoma. Pituitary 20036 81-87. (doi:10.1023/ B:PITU.0000004798.27230.ed)

42 Tanriverdi F, Yapislar H, Karaca Z, Unluhizarci K, Suer C \& Kelestimur F. Evaluation of cognitive performance by using P300 auditory event related potentials (ERPs) in patients with growth hormone $(\mathrm{GH})$ deficiency and acromegaly. Growth Hormone and IGF Research 200919 24-30. (doi:10.1016/j.ghir.2008.05.002)

43 Kauppinen-Mäkelin R, Sane T, Sintonen H, Markkanen H, Välimäki MJ, Löyttyniemi E, Niskanen L, Reunanen A \& Stenman UH. Quality of Life in treated patients with acromegaly. Journal of Clinical Endocrinology and Metabolism 200691 3891-3896. (doi:10.1210/ jc.2006-0676)

44 Webb SM, Badia X, Surinach NL \& the Spanish AcroQol Study Group. Validity and clinical applicability of the acromegaly quality of life questionnaire, AcroQoL: a 6-month prospective study. European Journal of Endocrinology $2006 \mathbf{1 5 5}$ 269-277. (doi:10.1530/eje.1.02214)

45 Wexler T, Gunnell L, Omer Z, Kuhlthau K, Beauregard C, Graham G, Utz AL, Biller B, Nachtigall L, Loeffler J et al. Growth hormone deficiency is associated with decreased quality of life in patients with prior acromegaly. Journal of Clinical Endocrinology and Metabolism 2009 94 2471-2477. (doi:10.1210/jc.2008-2671)

46 Badia X, Forsythe A, Nelson LM, Coles TM, McLeod LD \& Webb SM. Improvements in health-related quality of life in acromegaly with pasireotide LAR and octreotide LAR: results from a large, randomized, double-blind phase III trial. In Poster Presented at the International Society for Pharmacoeconomics and Outcomes Research (ISPOR), Berlin, Germany, 3-7 November 2012. Value in Health 201215 A505.

47 McLeod LD, Coon CD, Martin SA, Fehnel SE \& Hays RD. Interpreting patient-reported outcome results: US FDA guidance and emerging methods. Expert Review on Pharmacoeconomy Outcomes Research 2011 11 163-169. (doi:10.1586/erp.11.12) 
48 Andela CD, van Haalen FM, Ragnarsson O, Papakokkinou E, Johannsson G, Santos A, Webb SM, Biermasz NR, van der Wee NJ $\&$ Pereira AM. Mechanisms in endocrinology: Cushing's syndrome causes irreversible effects on the human brain: a systematic review of structural and functional magnetic resonance imaging studies. European Journal of Endocrinology 2015173 R1-R14. (doi:10.1530/EJE14-1101)

49 Badia X, Roset M, Valassi E, Franz H, Forsythe A \& Webb SM. Mapping CushingQoL scores to EQ-5D utility values using data from the European Registry on Cushing's syndrome (ERCUSYN). Quality of Life Research 201322 2941-2950. (doi:10.1007/s11136013-0396-7)

50 Roset M, Badia B, Forsythe A, Webb SM \& CushingQoL Development Group. Mapping CushingQoL scores onto SF-6D utility values in patients with Cushing's syndrome. Patient-Patient centered Outcomes Research 20136 103-111. (doi:10.1007/s40271-013-0010-7)

51 Nelson LM, Forsythe A, McLeod L, Pulgar S, Maldonado M, Coles T, Zhang Y, Webb SM \& Badia X. Psychometric evaluation of the Cushing's quality-of-life questionnaire. Patient-Patient centered Outcomes Research 20136 113-124. (doi:10.1007/s40271-013-0012-5)

52 Milian M, Honegger J, Teufel P, Wolf A \& Psaras T. Tuebingen $\mathrm{CD}-25$ is a sensitive tool to investigate health-related quality of life in Cushing's disease patients in the course of the disease. Neuroendocrinology 201398 188-199. (doi:10.1159/000355622)

53 Webb SM, Badia X, Barahona MJ, Colao A, Strasburger CJ, Tabarin A, van Aken MO, Pivonello R, Stalla G, Lamberts SW et al. Evaluation of health-related quality of life in patients with Cushing's syndrome with a new questionnaire. European Journal of Endocrinology $2008 \mathbf{1 5 8}$ 623-630. (doi:10.1530/EJE-07-0762)

54 Tiemensma J, Depaoli S \& Felt JM. Using subscales when scoring the Cushing's quality of life questionnaire. European Journal of Endocrinology 2016174 33-40. (doi:10.1530/EJE-15-0640)

55 Resmini E, Santos A, Gómez-Ansón B, Vives Y, Pires P, Crespo I, Portella MJ, de Juan-Delago M, Barahona MJ \& Webb SM. Verbal and visual memory performance and hippocampal volumes, measured by 3-Tesla magnetic resonance imaging, in patients with Cushing's syndrome. Journal of Clinical Endocrinology and Metabolism 201297 663-671. (doi:10.1210/jc.2011-2231)

56 Santos A, Resmini E, Crespo I, Pires P, Vives-Gilabert Y, Granell E, Valassi E, Gómez-Anson B, Martínez-Momblán MA, Mataró M et al. Small cerebellar cortex volume in patients with active Cushing's syndrome. European Journal of Endocrinology 2014171 461-469. (doi:10.1530/EJE-14-0371)

57 Ragnarsson O \& Johannsson G. Cushing's syndrome: a structured short- and long-term management plan for patients in remission. European Journal of Endocrinology 2013169 R139-R152. (doi:10.1530/ EJE-13-0534)

58 Badia X, Valassi E, Roset M \& Webb SM. Disease-specific quality of life evaluation and its determinants in Cushing's syndrome: what have we learnt? Pituitary 201417 187-195. (doi:10.1007/s11102-0130484-2)

59 Abraham SB, Abel BS, Rubino D, Nansel T, Ramsey S \& Nieman LK. A direct comparison of quality of life in obese and Cushing's syndrome patients. European Journal of Endocrinology 2013168 787-793. (doi:10.1530/EJE-12-1078)

60 Valassi E, Santos A, Yaneva M, Tóth M, Strasburger CJ, Chanson P, Wass JA, Chabre O, Pfeifer M, Feelders RA et al. The European Registry on Cushing's syndrome: 2-year experience. Baseline demographic and clinical characteristics. European Journal of Endocrinology 2011165 383-392. (doi:10.1530/EJE-11-0272)

61 Valassi E, Crespo I, Keevil BG, Aulinas A, Urgell E, Santos A, Trainer PJ \& Webb SM. Affective alterations in patients with Cushing's syndrome in remission are associated with decreased BDNF and cortisone levels. European Journal of Endocrinology 2017176 221-231. (doi:10.1530/EJE-16-0779)
62 Santos A \& Webb SM. Coping with Cushing's syndrome. The patients' perspectives. In Cushing's Disease an Often Misdiagnosed and Not So Rare Disorder, pp 170-185. Ed ER Laws Jr. Amsterdam: Elsevier Academic Press, 2017.

63 Gotch PM. Cushing's syndrome from the patient perspective. Endocrinology and Metabolism Clinics of North America 199423 607-617.

64 Curto L, Ferrau F \& Trimarchi F. Health-related quality of life in patients with Cushing's syndrome. Minerva Endocrinologica 201439 $75-77$.

65 Martínez-Momblán MA, Gómez C, Santos A, Porta N, Esteve J, Úbeda I, Halperin I, Campillo B, Guillaumet M, Webb SM et al. A specific nursing educational program in patients with Cushing's syndrome. Endocrine 201553 199-209. (doi:10.1007/s12020-015-0737-0)

66 van der Pas R, de Bruin C, Pereira AM, Romijn JA, Netea-Maier RT, Hermus AR, Zelissen PM, de Jong FH, van der Lely AJ, de Herder WW et al. Cortisol diurnal rhythm and quality of life after successful medical treatment of Cushing's disease. Pituitary 20126 536-544. (doi:10.1007/s11102-012-0452-2)

67 Hays RD, Sherbourne CD \& Mazel RM. The RAND 36-item health survey 1.0. Health Economics 19932 217-227.

68 Alcalar N, Ozkan S, Kadioglu P, Celik O, Cagatay P, Kucukyuruk B \& Gazioglu N. Evaluation of depression, quality of life and body image in patients with Cushing's disease. Pituitary 201316 333-340. (doi:10.1007/s11102-012-0425-5)

69 Tiemensma J, Biermasz NR, Middelkoop HA, van der Mast RC, Romijn JA \& Pereira AM. Increased prevalence of psychopathology and maladaptive personality traits after long-term cure of Cushing's disease. Journal of Clinical Endocrinology and Metabolism 201095 E129-E141. (doi:10.1210/jc.2010-0512)

70 Wagenmakers MAEM, Netea-Maier RT, Prins JB, Dekkers T, den Heijer M \& Hermus ARMM. Impaired quality of life in patients in longterm remission of Cushing's syndrome of both adrenal and pituitary origin: a remaining effect of long-standing hypercortisolism? European Journal of Endocrinology 2012167 687-695. (doi:10.1530/ EJE-12-0308)

71 Cesar de Oliveira Natiato E, Dutra Violante AH, Caldas D, Lamounier Filho A, Rezende Loureiro C, Fontes R, Schrank Y, Gomes de Souza R, Vaisman M, Guerra E et al. Quality of life in women with microprolactinoma treated with dopamine agonists. Pituitary 200811 247-254. (doi:10.1007/s11102-008-0091-9)

72 Kars M, van der Klaauw AA, Onstein CS, Pereira AM \& Romijn JA. Quality of life is decreased in female patients treated for microprolactinoma. European Journal of Endocrinology 2007157 133-139. (doi:10.1530/EJE-07-0259)

73 Kars M, Dekkers OM, Pereira AM \& Romijn JA. Update in prolactinomas. Netherlands Journal of Medicine 201068 104-112.

74 Frieboes RM, Murck H, Stalla GK, Antonijevic IA \& Steiger A. Enhanced slow wave sleep in patients with prolatinoma. Journal of Clinical Endocrinology and Metabolism 199883 2706-2710. (doi:10.1210/jcem.83.8.5016)

75 Biermasz NR, Joustra SD, Donga E, Pereira AM, van Duinen N, van Dijk M, van der Klaauw AA, Corssmit EP, Lammers GJ, van Kralingen KW et al. Patients previously treated for nonfunctioning pituitary macroadenomas have disturbed sleep characteristics, circadian movement rhythm and subjective sleep quality. Journal of Clinical Endocrinology and Metabolism 201196 1524-1532. (doi:10.1210/ jc.2010-2742)

76 Dekkers OM, van der Klaauw AA, Pereira AM, Biermasz NR, Honkoop PJ, Roelfsema F, Smit JW \& Romijn JA. Quality of life is decreased after treatment for nonfunctioning pituitary macroadenomas. Journal of Clinical Endocrinology and Metabolism 200691 3364-3349. (doi:10.1210/jc.2006-0003)

77 Capatina C, Christodoulides C, Fernandez A, Cudlip S, Grossman $\mathrm{AB}$, Wass JA \& Karavitaki N. Current treatment protocols can offer a 
normal or near normal quality of life in the majority of patients with non-functioning pituitary adenomas. Clinical Endocrinology 201378 86-93. (doi:10.1111/j.1365-2265.2012.04449.x)

78 Page RC, Hammersley MS, Burke CW \& Wass JA. An account of the quality of life of patients after treatment for non-functioning pituitary tumours. Clinical Endocrinology 199746 401-406. (doi:10.1046/j.1365-2265.1997.1400957.x)

79 Heald AH, Ghosh S, Bray S, Gibson C, Anderson SG, Buckler H \& Fowler HL. Long-term negative impact on quality of life in patients with successfully treated Cushing's disease. Clinical Endocrinology 2004 61 458-465. (doi:10.1111/j.1365-2265.2004.02118.x)

80 Höybye C, Ragnarsson O, Jonsson PJ, Koltowska-Häggström M, Trainer P, Feldt-Rasmussen U \& Biller BM. Clinical features of GH deficiency and effects of 3 years of GH replacement in adults with controlled Cushing's disease. European Journal of Endocrinology 2010 162 677-684. (doi:10.1530/eje-09-0836)

81 Karppinen A, Ritvonen E, Roine R, Sintonen H, Vehkavaara S, Kivipelto L, Grossman AB, Niemelä M \& Schalin-Jäntti C. Healthrelated quality of life in patients treated for non-functioning pituitary adenomas during the years 2000-2010. Clinical Endocrinology 201684 532-539. (doi:10.1111/cen.12967)

82 Andela CD, Scharloo M, Ramondt S, Tiemensma J, Husson O, Llahana S, Pereira AM, Kaptein AA, Kamminga NGA \& Biermasz NR. The development and validation of the Leiden Bother and Needs Questionnaire for patients with pituitary disease: the LBNQ-Pituitary. Pituitary 201619 293-302. (doi:10.1007/s11102-016-0707-4)

Received 18 January 2017

Revised version received 7 March 2017

Accepted 28 March 2017 